\title{
REVISIÓN CRÍTICA DE LA RETROACTIVIDAD COMO FACTOR OPERATIVO DE LA RESOLUCIÓN DEL CONTRATO*
}

\author{
EMILIO JOSÉ BÉCAR LABRAÑA** \\ Universidad Católica de la Santísima Concepción
}

\begin{abstract}
RESUMEN: El enunciado tradicional dice que la resolución del contrato por incumplimiento opera retroactivamente, de manera que este se reputa no haber existido jamás. Esta solución ha sido consagrada por las codificaciones de manera expresa o implícita, a partir de las normas sobre obligaciones condicionales o de acuerdo a los efectos de la nulidad y rescisión del contrato. Sin embargo, esta fórmula ha sido abandonada en el proceso de "Modernización del Derecho de las Obligaciones", adoptándose como regla general la irretroactividad, reservando la excepción para justificar las prestaciones restitutorias que deban efectuarse.

La primera solución es criticable, porque borra una serie de cláusulas esenciales para el tratamiento del incumplimiento y de ruptura del contrato. La segunda se ajusta más a las exigencias teóricas requeridas, aunque lo hace bajo una perspectiva algo exagerada, que intentaremos moderar.
\end{abstract}

Palabras Clave: Resolución del contrato por incumplimiento, retroactividad, obligaciones restitutorias.

ABSTRACT: Traditionally, the statement claims that the breach of contract resolution works retroactively; therefore it is understood that the contract has never existed. This solution has been adopted explicitly or implicitly by codifications, starting from rules on conditional obligations or according to the effects of nullity or contract cancellation.

However, this formula has been abandoned in the process of the "Modernization of Law of Obligations," except for justifying the restitutions that must occur.

The first solution can be criticized because it eliminates essential clauses for breach of contract. The second adjusts better to the theoretical requirements, although under an exaggerated perspective, which we will try to curb.

Key words: Contract resolution from breach of contract, retroactivity, restoring obligations.

Dedicado a Gabriel Luis Bécar Fierro

\footnotetext{
El presente trabajo corresponde a la versión original presentada al Primer Congreso Estudiantil de Derecho Civil (Santiago de Chile, Universidad de Chile, Facultad de Derecho, 2009). Una versión profundizada ha sido publicada, bajo el título "Revisión crítica de la retroactividad como factor operativo de la resolución del contrato: Algunas perspectivas de reforma para el Derecho chileno", por la Revista de Derecho, Universidad Católica de la Santísima Concepción (Concepción, Chile), N² 20, Vol. 2 (2009), pp. 155-179.

Este trabajo se enmarca en la ejecución de nuestra Memoria de Prueba para optar al Grado Académico de Licenciado en Derecho, bajo la dirección del profesor señor Bruno Caprile Biermann.

** Licenciado en Derecho. Universidad Católica de la Santísima Concepción.
} 


\section{INTRODUCCIÓN ${ }^{* * *}$}

1. La CISG marca un hito trascendental para el desarrollo del Derecho Civil contemporáneo ${ }^{1}$. En un esfuerzo notable por sintetizar la tradición del Derecho continental con las proposiciones del Common Law, se diseñó un conjunto normativo moderno y ágil, capaz de hacer frente a las exigencias de la actividad económica mundial.

Con la progresiva aprobación de esta Convención se da inicio a un importante período de reflexión que concluye en la necesidad de ajustar los esquemas afirmados desde los respectivos procesos de codificación y confirmados de una u otra manera por su interpretación doctrinaria y jurisprudencial. Tales esfuerzos han sido materializados en texto como los $\mathrm{PCCI}^{2}$ y los PECL ${ }^{3}$, entre otros.

2. Si miramos ahora la situación que se presenta en el Derecho Civil chileno, podremos advertir con agrado una considerable renovación en el análisis y aplicación del Derecho de las Obligaciones.

Es así que en la doctrina puede advertirse la presencia de incipientes estudios que buscan superar interpretaciones establecidas desde comienzos de siglo XX.

A nivel jurisprudencial persisten algunos relictos de interpretaciones todavía inadecuadas para las pretensiones del acreedor. Los avances en esta sede son más lentos que respecto de la doctrina.

En la cátedra podemos apreciar un esfuerzo todavía incipiente por renovar la visión del régimen de las obligaciones, lo que se manifiesta en algunos Planes de Estudio en las Facultades de Derecho. Con todo, este ángulo todavía avanza a un ritmo más lento que la propuesta en la doctrina.

\footnotetext{
*** Abreviaturas utilizadas en el artículo: ARCCFr. $=$ Del Contrato, de las Obligaciones y de la Prescripción. Anteproyecto de Reforma del Código Civil Francés (Libro III, Títulos III y XX); CCArg. = Código Civil de Argentina; CCB. = Código Civil de Brasil; CCBol. = Código Civil de Bolivia; CCch. = Código Civil de Chile; CCEsp. = Código Civil de España; CISG. = Convención de Naciones Unidas sobre los Contratos de Compraventa Internacional de Mercaderías; CNUDMI $=$ UNCITRAL $=$ Comisión de las Naciones Unidas para el Derecho Mercantil Internacional; CNUDMI, Compendio = Compendio de la CNUDMI sobre jurisprudencia relativa a la Convención de las Naciones Unidas sobre los Contratos de Compraventa Internacional de Mercaderias (en línea, http:// www.uncitral.org/uncitral/es/case_law/digests/cisg.html); CPCch. = Código de Procedimiento Civil de Chile; Comentarios del Secretariado CISG. = Secretariat Commentary on the 1978 Draft Convention on Contracts for the International Sale of Goods approved by the UNCITRAL (en línea, http://www.cisg.law.pace.edu/cisg/text/cisg-toc.html); PCCI. = Principios UNIDROIT sobre Contratos Comerciales Internacionales; PECL. = Principios del Derecho Europeo de Contratos; RDJ. = Revista de Derecho, Jurisprudencia y Ciencias Sociales y Gaceta de los Tribunales (Santiago, Chile). TS = Tribunal Supremo de España.

1 La literatura internacional sobre esta Convención es extensa. A nivel nacional: EsPINA O., Alberto y QUINTANA H., Alejandro. Compraventa Internacional de Mercaderías. Análisis de la Convención de las Naciones Unidas. Santiago, Chile: Editorial Jurídica de Chile, 1985. Vidal Olivares, Álvaro. La Protección del Comprador. Régimen de la Convención de Viena y su contraste con el Código Civil. Valparaíso, Chile: Ediciones Universitarias de Valparaíso, 2006.

2 Cf. Garro, Alejandro A. M. (director) y VeYTía P., Hernany (colab.). Principios UNIDROIT sobre los Contratos Comerciales Internacionales - 2a Edición- Roma, Italia: Universidad Nacional Autónoma de México - Instituto de Investigaciones Jurídicas, Unidroit, Centro Mexicano de Derecho Uniforme, 2004.

3 Cf. Díez-Picaso, Luis, Roca, Encarna, Morales Moreno, Antonio. Los Principios del Derecho Europeo de los Contratos. Madrid, España: Editorial Civitas, 2002.
} 
3. Los principales avances que se observan en esta modernización a la chilena del Derecho de las Obligaciones se encuentran exclusivamente en los presupuestos o condiciones de procedencia de la resolución del contrato, a tal punto de calificarla como la niña bonita del baile.

Empero, tal situación todavía no se hace presente en la segunda parte de esos estudios y que inciden en sus efectos. Comparativamente, los estudios en esta sede tienden a ser escasos y dedicados exclusivamente a la situación de los terceros. Si se pudiera destacar esta situación con una idea o imagen, podríamos decir que el estudio de esos efectos importa el pariente pobre de esta familia.

4. Nos parece que el estudio de esta parte es fundamental para el adecuado proceso de modernización del Derecho de las Obligaciones. Estos efectos son decisivos para configurar la institución en sí misma como una eficiente medida de que el acreedor puede hacer uso para obtener su liberación de un compromiso que ha fracasado por el incumplimiento que se ha hecho de él y la recuperación de los bienes y servicios que hubiere ejecutado a favor del deudor, para así acceder expeditamente al mercado a través de un nuevo oferente. Este proceso será inútil si no considera esa evaluación, porque no pueden ser atendidas, a un mismo tiempo, lógicas de fines del siglo XX bajo esquemas consagrados en el siglo XIX y continuadas a inicios del siglo XX.

5. Para esta exposición, hemos decidido presentar algunas inquietudes que resultan de la aplicación de ciertos enunciados con los cuales se trata de describir el efecto fundamental de la resolución: "la condición resolutoria cumplida opera retroactivamente". "La resolución aniquila el contrato, que se reputa no haber existido jamás”.

Los términos parecen bastante sencillos y obvios, pues revelan cuál es la verdadera naturaleza de la resolución, como causal de desaparición ab initio del vínculo, y que constituye la aplicación de una ficción ${ }^{4}$. Pero estas premisas chocan con algunas materias de importancia. Si se declara la resolución del contrato, ¿qué ocurre con todas y cada una de las estipulaciones aquí convenidas? ¿Podrá pagarse una pena autorizada en virtud de un contrato que debe desaparecer retroactivamente? ¿Deberá entenderse que el árbitro carecía de competencia para dictar él mismo la sentencia resolutoria?

Estas preguntas no se materializan en una gran preocupación. Por tanto, la alternativa debiera ser las siguientes: o no existe problema alguno, o se ha omitido alguna consideración de relevancia. Somos del segundo parecer, y esperamos que los lectores piensen de la misma manera.

6. Es así que describiremos cómo ha sido formulada la retroactividad como fundamento de la pretensión resolutoria, reiterando al efecto algunas consecuencias de esa afirmación (1). El Derecho Comparado contemporáneo ha brindado algunas alternativas moderatorias

\footnotetext{
4 Cf. Montory Barriga, Gonzalo. "Las Ficciones Jurídicas", en: Revista de Derecho, Nº 12, pp. 97-109. Concepción, Chile: Universidad Católica de la Santísima Concepción, Facultad de Derecho, 2004, pp. 97-109.
} 
de estos efectos tan potentes, optando por la irretroactividad (2); idea que si bien es plausible, se funda en algunos temores que entendemos injustificados (3).

\section{PRIMERA ETAPA: LA RETROACTIVIDAD COMO REGLA GENERAL}

7. Bajo esta fórmula, una vez firme la pretensión resolutoria, se produce la desaparición retroactiva del contrato, lo que desemboca en un efecto extintivo de las obligaciones, aunque por vía consecuencial, cual es la desaparición de la fuente de las obligaciones (CCch., arts. 578, 1437 y 2284).

8. Como se verá en esta sede, la retroactividad tiende a ser un efecto esencial y operativo de la resolución. Lo que no parece suficientemente claro es por qué se dice que es retroactiva; cuestión que en los códigos tiende a ser silenciada (1.1). Pero ese razonamiento ha derivado en una serie de problemas de técnica jurídica que deben ser explicados (1.2).

\subsection{Configuración de la REgla de la Retroactividad}

9. Una revisión de la materia nos permite afirmar que la cuestión se cierra sobre la base de dos consideraciones. Por una parte, conceder la retroactividad de la resolución a partir de las reglas sobre obligaciones condicionales (1). Por otra, su asimilación con los efectos de la declaración de nulidad y de rescisión del contrato (2).

\section{(1) La regla de la retroactividad obtenida a partir de las obligaciones condicionales}

10. La primera fórmula empleada por las legislaciones, particularmente aquellas influenciadas por el Código Civil de Francia, consistió del tratamiento del incumplimiento como una "condición resolutoria tácita" contenida en los contratos bilaterales.

Este régimen se inserta dentro del estatuto de las obligaciones condicionales, en los cuales se debe responder a la situación en que se encuentran las partes una vez que la respectiva condición ha sido "cumplida".

En esta sede veremos algunos modelos codificados que se diseñaron a partir de la lógica de la "condición resolutoria tácita", como lo fueron el francés (1.1) y el español (1.2), concluyendo nuestra revisión con el caso chileno (1.3). Pero debemos destacar que incluso en códigos contemporáneos y reformados se aplica la misma lógica (1.4).

\section{(1.1) Derecho Francés}

11. Se advierte que el art. 1184 CCfr. nada dice sobre si hay o no retroactividad, ni tampoco si afecta o no a la integridad del contrato. Debido a la situación anterior, la res- 
puesta de la retroactividad ha tenido que ser obtenida a partir de las reglas de las obligaciones condicionales (CCfr., art. 1183) ${ }^{5}$, al igual que en el sistema jurídico chileno.

12. Revisando el estatuto de las obligaciones condicionales, salta rápidamente a la vista el inc. $1^{\circ}$ del art. 1179 CCfr.; norma tiene como antecedente inmediato la doctrina sustentada por Pothier, quien acogía el principio ${ }^{6}$. En consecuencia, corresponde que los contratantes se efectúen las prestaciones mutuas necesarias para que ellas terminen de ser restablecidas a un momento anterior a la celebración del contrato.

13. Por su parte, la jurisprudencia ha seguido el parecer indicado. En un principio, sostuvo que la resolución operaba de la misma manera que la condición resolutoria expresa $(\text { u ordinaria })^{7}$-es decir, retroactivamente- de manera que las partes deben ser repuestas a un mismo estado equivalente a si la obligación no hubiese existido jamás ${ }^{8}$, invocando al efecto el art. 1183 CCfr.

Contemporáneamente, la jurisprudencia francesa mantiene la idea que la resolución opera con efecto retroactivo. En este sentido se han pronunciado la Sala Comercial y la Tercera Sala Civil de la Corte de Casación?.

\section{(1.2) Derecho Español}

14. El régimen resolutorio español se estructura de una manera muy similar al chileno, configurando el incumplimiento de un contrato con "obligaciones recíprocas" como el "cumplimiento de una condición resolutoria" (CCesp., art. 1124). Sin embargo, las vacilaciones serán todavía mayores en este sistema ${ }^{10}$.

15. Bajo el amparo de esta sede, deben considerarse dos normas importantes. Por un lado, el art. 1120 CCesp., que menciona que los efectos de la obligación condicional de dar, "una vez cumplida la condición, se retrotraen al día de la constitución de aquella”. En segundo lugar, y aplicada específicamente a la condición resolutoria cumplida, debe citarse el art. 1123 CCesp., el cual indica que cuando las obligaciones "tengan por objeto resolver

\footnotetext{
5 Cf. Rochfeld, Judith. Inejecución de las Obligaciones (arts. 1157 a 1160 - 1). En: VV.AA. Del Contrato, de las Obligaciones y de la Prescripción. Anteproyecto de Reforma del Código Civil Francés. Libro III, Títulos III y XX (Trad. Fernando Hinestrosa). Bogotá, Colombia: Universidad Externado de Colombia, 2006, p.108.

6 Pothier, Robert Joseph. Tratado de las Obligaciones (Trad. M. C. De las Cuevas). São Paulo, Brasil: Editorial Heliasta S. R. L., 1993, con cita de fuentes romanas.

7 Cf. REQ. 5.12.1881, S. 82, 1, 110, citado en Planiol, Marcel, RiPERT, Georges, y EsmeIn, Paul. Traité Pratique de Droit Civil Français. París, Francia: Librairie Générale de Droit et de Jurisprudente, 1930, T. VI, p. 600.

8 Ibid., p. 600.

9 Cf. CAS. COM., 12.10.1982, JCP 1984, éd. G, II, 20166, nota SIGNORET; Defrénois 1983, p. 876, obs. Jean - Luc AUBERT. CAS. $3^{\text {E }}$ CIV., 11.1.1984, JCP 1984, éd. G, IV, 88; Defrénois 1984, p. 1067, obs. SOULEAU.

10 Esta situación fue particularmente destacada por la profesora FENOY PICÓN, Nieves. Congreso Internacional "Modernización del Derecho de las Obligaciones en Europa y Latinoamérica". Viña del Mar, Chile: Pontificia Universidad Católica de Valparaíso, Facultad de Derecho, Programa de Doctorado en Derecho, 26 y 27 de agosto de 2008.
} 
la obligación de dar, los interesados, cumplidas aquéllas, deberán restituirse lo que hubiesen percibido".

16. Las normas nada mencionan en cuanto a la desvinculación de los contratantes, en cuanto estos quedan liberados de sus respectivas obligaciones. De esta manera, el primer y elemental efecto de la resolución, consistente del liberatorio, queda silenciado.

En un segundo momento, queda desplazado por una preocupación más profunda del codificador español, y que consiste en las prestaciones realizadas por los contratantes. De esta manera, se presenta en su lugar un desarrollado estatuto de los efectos restitutorios entre los contratantes (CCesp., arts. 1.120, 1.222 y 1.123).

\section{(1.3) Derecho Chileno}

17. En el caso del derecho chileno, el art. 1489 CCch. solo consagra el derecho de reclamar la resolución frente al incumplimiento de parte de uno de los contratantes.

Ante al silencio adoptado por el legislador, deberá recurrirse a las normas sobre obligaciones condicionales. Pero la cuestión es silenciada igualmente en esta sede.

18. Se promueve un importante debate en cuanto al verdadero criterio admitido por el codificador a partir de una serie de preceptos esparcidos en el Código (1.3.1). Sin embargo, a nuestro entender hubo un cambio en el contexto del establecimiento de las normas en controversia (1.3.2).

\section{(1.3.1) Descripción del debate y algunas aplicaciones}

19. En forma tradicional, se indica que la resolución provoca la "desaparición retroactiva del contrato", de manera que se reputa que nunca existión ${ }^{11}$.

Con base al art. 1487 CCch., aplicable a las diversas modalidades de condición resolutoria, se colige la presencia de la retroactividad ${ }^{12}$.

20. La jurisprudencia también es conteste en asignarle efecto retroactivo a la resolución. En la causa Vicente c. Banco Sud Americano y Figueroa ${ }^{13}$, la Corte de Apelaciones de Chillán destaca la retroactividad de la resolución que funda en el art. 1487 CCch., que provoca la desaparición de la obligación y las restituciones pertinentes (C. $6^{\circ}$ ). En el mismo sentido puede consultarse la causa Bifactoring S. A. c. Lepe y Álamo Limitada ${ }^{14}$ (C. $\left.6^{\circ}\right)$.

11 Por todos: Alessandri R., Arturo, SOMARriva U., Manuel y VodAnOvic H., Antonio. Tratado de las Obligaciones. Volumen de las Obligaciones en General y su diversas clases -2a Edición-Santiago, Chile: Editorial Jurídica de Chile, 2001, T. I, No 375, p. 292.

12 Alessandri R., Arturo. De la Compraventa y de la Promesa de Venta -2a Edición-Santiago, Chile: Editorial Jurídica de Chile, 2003, T. II, Vol. 2, No 1750, pp. 557-558.

13 Vicente c. Banco Sud Americano y Figueroa, Corte de Apelaciones de Chillán, 30.12.2003, Rol № 24.898, en LegalPublishing 34334; Corte Suprema, 30.5.2006, Rol No $494-04$.

14 Bifactoring S. A. c. Lepe y Álamo Limitada, Corte Suprema, 15.1.2008, Rol № 65-06, en LegalPublishing 38345. 
(1.3.2) Revisión histórica del art. 1487 CCch. como fundamento de la retroactividad de la resolución del contrato

21. Una revisión del proceso de codificación chileno permite apreciar un drástico y explícito cambio de técnica en materia de retroactividad.

Es así que en el Pyto. atrib. Egaña se indica que cumplida que sea la condición resolutoria expresa, "por el solo efecto de ella, se reputa de no haber existido jamás" (Lib. De los Contratos y Obligaciones Convencionales, tít. III, art. 42), criterio que persistió en el Pyto. 1841-1845 (Lib. IV, tít. III, art. 13), en el Pyto. 1846-1847 (art. 43) y en el Pyto. 1853 (art. 1664 inc. $\left.1 .^{\circ}\right)$. Las alteraciones se producen en el contenido de las restituciones.

22. La redacción actual se plasma en el Pyto. Inéd., que en su art. 1664 decía que por el cumplimiento de la condición resolutoria "deberá restituirse lo que se hubiere recibido bajo tal condición”.

La redacción se mantuvo en el Proyecto aprobado por el Congreso Nacional y no fue alterado por el señor Bello en las enmendaduras que con posterioridad le introdujo.

\section{(1.4) Situación del Código Civil de Argentina}

23. Ante la carencia de una referencia explícita a la retroactividad en el art. 1204 CCArg., la doctrina argentina ha afirmado que la resolución del contrato opera retroactivamente, de manera que "el incumplimiento reobra en el tiempo deshaciendo la relación contractual desde el origen" ${ }^{15} \mathrm{y}$, como consecuencia de lo anterior, deberán restituirse recíprocamente lo que hubieren recibido de su contraparte ${ }^{16}$.

24. Es importante destacar el art. 1374 CCarg., que reglamenta los efectos de la resolución del contrato de compraventa en que se estipuló un pacto comisorio, dice "se reputará hecha bajo una condición resolutoria", por lo que "los efectos de la obligación se retrotraen al día en que se contrajo" (CCarg., art. 543).

Algunos autores entienden que aquí se encuentra el fundamento de la retroactividad, de manera que cabe justificarla bajo los efectos de la condición resolutoria cumplida ${ }^{17}$.

\footnotetext{
15 Morello, Augusto Mario. Ineficacia y Frustración del Contrato (Colab. Pedro Rafael De la Colina) -2a Edición- La Plata, Argentina: Librería Editora Platense y Editorial LexisNexis Abeledo- Perrot, 2006, XVIII, p. 249.

16 Cf. BORDA, Guillermo A. Tratado de Derecho Civil: Contratos (Colab. Alejandro Borda). Buenos Aires, Argentina: Editorial LexisNexis Abeledo-Perrot, 2005, T. I, No 308-11, p. 229.

17 Ibid.
} 
(2) La regla de la retroactividad concebida a partir de las normas sobre nulidad y rescisión de los contratos

25. La segunda técnica doctrinaria que ha sido invocada para justificar la retroactividad ha sido relacionar los efectos de la resolución con los derivados de la nulidad y rescisión del contrato (2.1), lo cual ofrece ciertas ventajas (2.2).

\section{(2.1) Consagración}

26. Esta tesis ha sido particularmente debatida en el Derecho español (2.1.1) y argentino (2.1.1). Antes de plantear el debate para el Derecho chileno (2.1.4), indicaremos algunas proposiciones que indirectamente apuntan hacia ese mismo sentido (2.1.3).

\section{(2.1.1) España}

27. La doctrina española ha podido colegir que la resolución es retroactiva de acuerdo al inc. final del art. 1.124 CCesp., al regularse la situación de los terceros poseedores ${ }^{18}$.

28. La jurisprudencia reconoció tempranamente la retroactividad ${ }^{19}$ a partir del "espíritu general de la legislación"; colegida no solamente de los efectos de la rescisión, sino también los de la condición resolutoria expresa (CCesp., art. 1123) ${ }^{20}$.

\section{(2.1.2) Argentina}

29. Algunos autores entienden que la retroactividad de la resolución del contrato debe buscarse por analogía en el efecto de la nulidad, que opera retroactivamente ${ }^{21}$.

30. La jurisprudencia adopta una solución bastante "diplomática" ya que busca responder a esta interrogante a partir de un principio que extrae tanto de las reglas sobre ineficacia intrínseca como del pacto comisorio en la compraventa.

\section{(2.1.3) Codificaciones recientes}

31. En el Derecho Comparado parece enfocarse esta alternativa de manera más o menos explícita, avanzando las legislaciones hacia la consagración de un sistema unitario de cau-

\footnotetext{
18 Por todos: Clemente Meoro, Mario. La Resolución de los Contratos por Incumplimiento. Estudio comparativo, doctrinal y jurisprudencial del Derecho Inglés y del Derecho Español. Valencia, España: Editorial Tirant lo Blanch, 1992, \$48, p. 243.

19 TS., sent. 10.3.1950; 14.11.1962; 21.11.1963; 23.2.1964 y 16.10.1967, citado en CASTÁN TOBEÑAS, José. Derecho Civil Español, Común y Foral: Derecho de las Obligaciones. La Obligación y el Contrato en General (revisada y puesta al día por Gabriel García Cantero) T. III, \$ LXVIII, Nº 2 -16a Edición- Madrid, España: Editorial Reus, 1992, p. 151.

20 TS., sent. 31.5.1985, en Repertorio Aranzadi 2, 837; 17.6.1986, en Repertorio Aranzadi 3, 554, cit. ClemENTE MEORO, Mario, op. cit. (n.18), $\$ 48$, p. 242.

21 Cf. Morello, Augusto Mario, op. cit. (n. 15), XVIII, pp. 248-249.
} 
sales de eliminación del contrato. Tal es el caso de los dos principales Proyectos de Reforma en Francia, que son el ARCCFr. y el Projet de Réforme du Droit des Contrats.

Algunas codificaciones latinoamericanas disponen el tratamiento de la resolución como una causal de eliminación de los contratos, tras su sistematización simultánea con causales de ineficacia de los contrato. Es lo que ocurre con el Código Civil de Bolivia y el nuevo texto de Brasil (2002).

\section{(2.1.4) Chile}

32. Algunos autores extrañan en materia de resolución del contrato una norma como el art. 1687 CCch., que a propósito de los efectos de la declaración de nulidad, sí consagraría la retroactividad con que ésta opera ${ }^{22}$. De esta manera, para la resolución se reclama una misma respuesta; debe razonarse como si el contrato no se hubiera llevado jamás a cabo ${ }^{23}$.

33. Una sentencia nacional dictada en el año 1909 indicaba que el actor carecía del derecho para exigir "del actual poseedor la restitución del predio rural indicado, que según los referidos artículos 1687 y 1689 es un efecto legal de la resolución del contrato”24.

A pesar de este error -el fallo discutía la situación de los efectos de la nulidad y no de la resolución- se destaca por la doctrina la similitud de sus efectos en lo que respecta a la retroactividad.

\section{(2.2) Ventajas}

34. La interpretación aquí explicada obedece a la necesidad de aplicar ventajas que dicen relación con las prestaciones restitutorias y "la eficacia o no de los actos de administración y disposición de las cosas objeto de aquellas prestaciones, realizados por las partes hasta el momento de la resolución" 25 .

35. En el caso de nuestro país, en sede de obligaciones condicionales no se admite la restitución de los frutos, los que pertenecen por regla general al deudor que debe restituir esos bienes una vez que se verifique la condición resolutoria (CCch., art. 1488).

En cambio, esa regla no existe en materia de nulidad y rescisión, en las cuales se apli-

22 Cf. Castelblanco Koch, Mauricio Javier. Las Obligaciones Restitutorias del Código Civil y la Inflación. Santiago, Chile: Editorial Jurídica de Chile, 1979, № 100, pp. 99-100. LÓPEZ SANTA MARÍA, Jorge. Obligaciones y Contratos frente a la Inflación. Santiago, Chile: Editorial Jurídica de Chile, 1978, N 78, pp. 157-158.

23 Cf. AlessAndri B., Arturo. La Nulidad y la Rescisión en el Derecho Civil Chileno -2a Edición- Santiago, Chile: Ediar Editores Ltda., s/f, T. II, $N^{\circ} 1253$, pp. 1082-1083.

24 Cf. RDJ., T. VII, $2^{\text {a }}$ parte, sec. $1^{\text {a }}$, p. 267, cit. CASTELBLANCO, Mauricio, op. cit. No 100 , p. 100, n. 156.

25 Por todos: PANTAleón, Fernando. "Resolución por Incumplimiento e Indemnización”, en: Anuario de Derecho Civil, T. XLII, fascículo IV. Madrid, España: Ministerio de Justicia y Consejo Superior de Investigaciones Científicas, octubre-diciembre, 1989, N 4, p. 1154. 
can las prestaciones restitutorias de la acción reivindicatoria, que se subordinan a requisitos de buena o mala fe (CCch., art. 1687).

\subsection{LAS DificultadeS QUE HA PLANTEADO LA TESIS DE LA DESAPARICIÓN DEL CONTRATO}

36. Sea que la retroactividad de la resolución se configure en clave de obligaciones condicionales o de la nulidad, el modelo significa tratar al contrato como un acto "nunca celebrado" (quod nullum est nullum producit effectum), lo que supone configurarla como un supuesto de "ineficacia extrínseca" que no se compadece con las características de la resolución, que supone un acto válido ${ }^{26}$.

37. Supone la cuestión varias dificultades que la doctrina no explica (1), las que se tratan de superar con algunos "correctivos" (2).

\section{(1) Dónde se presentan los problemas}

38. Algunos problemas concretos de la retroactividad se encuentran en su armonización con la pretensión indemnizatoria (1.1), la admisión de la cláusula penal (1.2) y en materia de arbitraje (1.3).

(1.1) Armonización de la resolución con la indemnización de perjuicios

39. La retroactividad sería tan poderosa que conduciría a la imposibilidad jurídica de reclamar la indemnización de perjuicios por el incumplimiento del contrato. Esto, porque no queda claro si debe igualarse a lo que habría recibido el acreedor en caso de haberse cumplido con el contrato (interés positivo) o de situarlo en un estado anterior a la celebración del contrato, como si este no se hubiere realizado (interés negativo) ${ }^{27}$.

(1.2) Situación de la cláusula penal

40. Las partes estipulan que en caso de incumplimiento del contrato, el acreedor tendrá derecho a cobrar la pena que ha sido convenida al efecto. En la sentencia definitiva, el tribunal acogerá la pretensión resolutoria y, según lo permita el caso, se acogerá también el cobro de la pena. ¿Es procedente?

41. En nuestro sistema se trata de una materia que ha sido poco abordada y los tribunales tienden a declarar resuelto el contrato y aplicar las penas que han sido convenidas ${ }^{28}$.

\footnotetext{
26 TS., sent. 28.6.1977, citado en Clemente MeOro, Mario, op. cit. (n.18), \$ 48, pp. 248-249.

27 Por todos: PANTALEÓn, Fernando, op. cit. (n.25), p. 1153.

28 A modo de ejemplo: Rivera Marín, José Fidel c. Muñoz Gallardo, Pedro Antonio, Corte Suprema, 30.6.2003, Rol N ${ }^{\circ} 3.643-$ 2002, en RDJ., T. C, № 1 (enero / junio 2003), $2^{\circ}$ Parte, Sec. $1^{\mathrm{a}}$, pp. 104-107.
} 
La doctrina es bastante peculiar en esta materia, pues aunque entiende que la estipulación de la pena no importa renuncia de la pretensión resolutoria, una vez que se la declara ya no es posible obtener su pago; la desaparición retroactiva del contrato incumplido acarrea la desaparición consecuencial de todos los accesorios, incluyendo la cláusula penal ${ }^{29}$.

42. Meritoria es una sentencia dictada por la Corte de Apelaciones de Concepción, en causa caratulada Moroni c. Moreno ${ }^{30}$, en la cual justifica dogmáticamente cuáles fueron las razones que permiten rechazar la invocación de la accesoriedad en su interpretación tradicional y de destacar la relevancia de esta pregunta.

Es así que no debe olvidarse el rol de avaluación anticipada y convencional de los perjuicios, ítem este último que siempre podrá pedirse conjuntamente con el cumplimiento o la resolución del contrato (C. $\left.17 .^{\circ}\right)$. Agrega que "a nadie le extraña" la concesión conjunta de la resolución y la pena, porque la accesoriedad de la pena se guía por lo dicho para la indemnización legal de perjuicios y no por la tradicional concepción de accesoriedad (C. 19. ${ }^{\circ}$ ).

Esta sentencia fue casada por la Corte Suprema (2.12.1997, Rol N³.518-96), debido a los defectos formales en que incurría, pero no puede ignorarse el valor doctrinario de lo allí resuelto.

\section{(1.3) Situación del arbitraje}

43. Las partes han estipulado que todas las dificultades derivadas del incumplimiento de este contrato serán sometidas al conocimiento y decisión de un árbitro. Una vez concluido el procedimiento arbitral, se dicta el laudo declarándose la resolución del contrato. El demandado apela de esta sentencia y alega ante el tribunal de alzada que el árbitro carecía de jurisdicción para haber declarado la resolución del contrato. ¿Es posible?

44. La fuente del arbitraje es un contrato que respecto del incumplido tiene carácter accesorio. Por tanto, si se entiende que nunca existió, entonces decae la fuente de autoridad del arbitraje, de manera que todas y cada una de las resoluciones dictadas en este procedimiento, incluyendo la sentencia arbitral, son nulas.

45. La solución alcanza ribetes excesivos. De aceptarse determinaría la inutilidad de someter estos asuntos a la justicia arbitral, o que el tribunal tendría que declararse incompetente para declarar la resolución del contrato. Esto entorpece el procedimiento y desemboca en una serie de costos que precisamente con esta fórmula se pretendían evitar.

29 Por todos: GATICA PACHECO, Sergio. Aspectos de la Indemnización de Perjuicios por Incumplimiento del Contrato (Del incumplimiento de las obligaciones contractuales; de los perjuicios y de su liquidación judicial, legal y convencional. De la cláusula penal. Artículos 1556, 1558, 1559 y 1535 a 1544 del Código Civil). Santiago, Chile: Editorial Jurídica de Chile, 1959, № 325, pp. 430-431.

30 Moroni Ortega, Guillermo c. Moreno Lara, Rolando, Corte de Apelaciones de Concepción, 29.7.1996, Rol N 317-93, en Legal Publishing 14967. 


\section{(2) Cómo se han tratado de solucionar}

46. Se han propuesto algunos correctivos de carácter doctrinario (2.1) y legislativo (2.2).

\section{(2.1) Correctivos doctrinarios}

47. Explicaremos la interpretación seguida por la doctrina francesa (2.1.1) y alemana $(2.1 .2)$.

\section{(2.1.1) Doctrina francesa}

48. Ya los profesores Planiol y Ripert introducían una crítica a la regla de la retroactividad, indicando en su lugar que el contrato "deja de producir sus efectos".

Corresponde efectuar una "liquidación" en caso que alguna de las prestaciones haya sido cumplida. Sería imposible pretender que las prestaciones nunca se hubiesen ejecutado ${ }^{31}$.

\section{(2.1.2) Doctrina alemana}

49. Inicialmente se sostuvo que el efecto atribuido a la resolución consistía de la "extinción total de la relación obligatoria”32.

Este esquema se mantuvo bajo la Ley de Modernización del Derecho Alemán de las Obligaciones (2002). Estando conscientes los reformistas de la situación, se omitió explícitamente este efecto liberatorio (Befreiungswirkung) ${ }^{33}$.

50. La cuestión se decide bajo una fórmula más bien indirecta y artificial ${ }^{34}$, por la consagración de una particular relación obligatoria que se haga cargo de las prestaciones que han sido cumplidas por los contratantes, mientras que por la resolución se extingue el vínculo obligatorio hacia el futuro.

\section{(2.2) Correctivos legislativos}

51. A nuestro entender, hay dos especies de corrección a la retroactividad en las codificaciones del siglo XX; el momento en que se entiende resuelto el contrato (2.2.1) y la aplicación de la retroactividad solamente para los contratos de ejecución instantánea (2.2.2).

31 Cf. Planiol, Marcel, Ripert, Georges y Esmein, Paul, op. cit. (n. 7), T. VI, N 433, pp. 600-601.

32 Cf. Hedemann, J. W. Derecho de Obligaciones (Trad. Jaime SAnTos BRIZ). Madrid, España: Editorial Revista de Derecho Privado, 1958, Vol. III, $\$ 17$, p. 144 .

33 Cf. Ehmann, Horst y SuTSChet, Holger. La Reforma del BGB. Modernización del Derecho Alemán de Obligaciones (Trad. Claudia López Díaz y Ute Salach de Sánchez). Bogotá, Colombia: Ediciones Universidad Externado de Colombia, 2006, p. 182.

34 En contra: Zimmermann, Reinhard. The New German Law of Obligations. Historical and Comparative Perspectives. Oxford, Reino Unido: Oxford Claredon Press, 2005, Nº 4, p. 73. 
(2.2.1) Reformulación del momento en que se entiende resuelto el contrato

52. Consiste de una técnica legislativa introducida para el CCper. (1984). En el inc. $2 .^{\circ}$ del art. 1372, indica que sus efectos "se retrotraen al momento en que se produce la causa que la motiva".

Algunos autores han diferenciado entre la manera en que opera la rescisión y la resolución del contrato, porque en el primer caso "se declara judicialmente, pero los efectos de la sentencia se retrotraen al momento de la celebración del contrato" (CCper., art. 1372 inc. $1 .^{\circ}$ ); en cambio, la segunda no podría operar retroactivamente puesto que se la hace operar a partir de una causal sobreviniente a su celebración ${ }^{35}$. Sin embargo, entendemos que el legislador peruano ha explícitamente autorizado la retroactividad, aunque "atenuada" o "incompleta”.

53. Esta solución no deja de ser interesante, toda vez que permite la subsistencia de todas las cláusulas complementarias que hemos referido. Empero, hay dificultades para entender cómo es posible obtener la restitución de las prestaciones ejecutadas en el tiempo previo.

(2.2.2) Procedencia exclusiva de la retroactividad para los contratos de ejecución instantánea

54. La doctrina tiende a situar como excepción a los contratos de ejecución sucesiva y escalonada, respecto de los cuales se explica que la liberación no es retroactiva (ex nunc) porque no es posible obtener la restitución de las prestaciones ejecutadas por alguna o ambas partes ${ }^{36}$.

55. Este criterio se plasmó a texto positivo en uno de los Códigos relevantes de principios de siglo XX, y que lo constituyó el Código Civil de Italia de 1942 (art. 1458).

56. A partir de esta norma se ha extendido la fórmula hacia una serie de Códigos y reformas de la segunda mitad del siglo pasado.

$\mathrm{El}$ inc. $1^{\circ}$ del art. 1204 CCarg. formula una especificación en cuanto a las restituciones, que se refiere a aquellos "contratos en que se hubiese cumplido parte de las prestaciones", en cuyo caso "las que se hayan cumplido quedarán firmes y producirán, en cuanto a ellas, los efectos correspondientes”. Esta expresión ha sido entendida como referida tanto a los contratos de

\footnotetext{
35 Cf. Bonivento FernándeZ, José Alejandro. Breves apuntaciones al Libro VII -Fuentes de las Obligaciones- del nuevo Código Civil del Perú 1984. En: VV. AA. El Código Civil Peruano y el sistema jurídico latinoamericano. Ponencias presentadas en el Congreso Internacional celebrado en Lima del 9 a 11 de agosto de 1985 organizado por la Facultad de Derecho y Ciencias Políticas de la Universidad de Lima y la Associazione di Studi Sociali Latinoamericani (ASSLA). Lima, Perú: Cultural Cuzco Editores, 1986, $\mathrm{N}^{\circ}$ 6, p. 359 .

36 Para el Derecho chileno: Alessandri, Arturo, SomarRiva, Manuel y VOdANOVIC, Antonio, op. cit. (n.11), T. I, N 376, pp. 293-294. Para el Derecho francés: Josserand, Louis. Derecho Civil. Teoría General de las Obligaciones (revisado y complementado por André BRUN; traducción Santiago Cunchillos y Manterola). Buenos Aires, Argentina: Ediciones Jurídicas EuropaAmérica, T. II, Vol. 1, N 385, pp. 269-270.
} 
prestaciones periódicas o ejecución continuada, así como también a los contratos cuyas prestaciones sean divisibles y se hubieren cumplido en forma parcial, recíproca y equivalente ${ }^{37}$.

57. Una solución equivalente se quiso plasmar en el CCbol., que en el ap. I de su art. 574 se indica que la resolución "surte efectos con carácter retroactivo, salvos los contratos de ejecución sucesiva o periódica en los cuales la resolución no alcanza a las prestaciones ya efectuadas".

Pero la retroactividad parece perder peso y relevancia bajo el actual proceso de modernización del Derecho de las obligaciones, como explicaremos en esta segunda parte.

\section{SEGUNDA ETAPA: PROPUESTAS DEL DERECHO COMPARADO Y ALGUNAS DIFICULTADES QUE PROPONE. EL PRINCIPIO DE IRRETROACTIVIDAD DE LA RESOLUCIÓN DEL CONTRATO}

58. En cuanto a la resolución del contrato, no solamente se reformularon sus presupuestos, sino también sus efectos. En este último caso, la alteración de la tradicional regla de la retroactividad es importante, pues parece describirse una fórmula completamente diversa.

En esta segunda parte de nuestra exposición, tendremos la posibilidad de destacar cómo ha sido formulada la irretroactividad como pretendida regla general (2.1). Pero veremos que se trata de un atributo técnico objeto de controversia bajo los actuales textos de Derecho Privado (2.2).

\subsection{LA CONSAGRACIÓN COMO REGLA GENERAL DE LA IRRETROACTIVIDAD EN LOS EFECTOS DE LA RESOLUCIÓN DEL CONTRATO}

59. Se trata de una tendencia que es común, en que es punto decisivo el criterio adoptado por la CISG (1), al que luego se fueron plegando los PECL (2) y los PCCI (3).

\section{(1) El estado del debate en la CISG}

60. De acuerdo al ap. 1 del art. 81, el principal efecto que desencadena la resolución es el desvinculador, de manera que los contratantes quedan liberados de su obligación de cumplir el contrato ${ }^{38}$.

A partir de este efecto, la jurisprudencia ha colegido que el contrato resuelto no queda totalmente sin efecto en virtud de la resolución, sino que se transforma en una relación que

\footnotetext{
37 Cf. BORDA, Guillermo, op. cit. (n. 16), T. I, No 308 . 11, pp. 229-230 y n. 605. Morello, Augusto, op. cit. (n. 15), XVIII, p. 251.

38 Cf. EsPInA, Alberto y QuinTANA, Alejandro, op. cit. (n. 1), p. 203.
} 
llega a su término39, o que "convierte la relación contractual en una relación de restitución (de desenlace $)^{40}$.

61. Como se apreciará de la redacción del ap. 1 del art. 81 CISG., lo primero que indica es que "la resolución del contrato liberará a las dos partes de sus obligaciones". Por tanto, el primer objeto de atención del efecto liberatorio mira hacia el futuro. No obstante, cabe preguntarse si es posible deshacer las consecuencias que la obligatoriedad del contrato impuso a los contratantes.

De acuerdo al mismo ap. 1 del art. 81 CISG., subsisten como obligaciones "la indemnización de daños y perjuicios que pueda ser debida". Tampoco quedan afectadas "las estipulaciones del contrato relativas a la solución de controversias ni a ninguna otra estipulación del contrato que regule los derechos y obligaciones de las partes en caso de resolución”. Debe advertirse que este texto no tendría carácter taxativo en cuanto a las excepciones ${ }^{41}$.

\section{El estado del debate en los PECL}

62. El efecto desvinculatorio queda establecido en su art. 9:305, titulado "Efectos de la resolución".

Es afirmado que el PECL no atribuye efecto retroactivo a la resolución, puesto que su desaparición impide justificar las obligaciones indemnizatorias (ap. 1) y la vigencia de las cláusulas pactadas para el caso de incumplimiento (ap. 2). Su sede simplemente son las restituciones ${ }^{42}$.

\section{(3) El estado de debate en los PCCI}

63. La cuestión se trata en el art. 7.3.5 (“Efectos generales de la resolución”). La principal idea que se quiso plasmar en estos Principios es la irretroactividad, la que solo excepcionalmente tiene cabida, para los efectos restitutorios. Esto se observa claramente en sus Comentarios $^{43}$, donde se destaca:

1. Que la "regla general" consiste en que la resolución viene a producir sus efectos hacia el futuro, de manera que los contratantes quedan liberados de su obligación de "efectuar y recibir prestaciones futuras".

39 Cf. Oberster Gerichtshof, Compendio, Austria: CNUDMi, 26.6.1999, Art. 81 ap. 1, No 1, p. 2.

40 Cf. Landgericht Düsseldorf, Compendio, Austria: CNUDMI, 11.10.1995, Art. 81 ap. 1, No 1, p. 2.

41 Cf. Comentarios del Secretariado CISG, art. 81, ap. 1, $\mathrm{N}^{\circ} 6$.

42 Díez - Picaso, Luis, Roca, Encarna y Morales Moreno, Antonio, op. cit. (n. 3), No XI, p. 366. Zimmermann, op. cit. (n. 34), p. 73.

43 Cf. Garro, Alejandro y Veytia, Hernany, op. cit. (n. 2), art. 7.3.5, p. 236. 
2. Que no obstante el contrato llegue a su fin, no por ello se debe privar al contratante interesado de la pretensión indemnizatoria por los daños generados a consecuencia del incumplimiento del contrato.

3. Pueden existir disposiciones contractuales "que sobrevivan a su resolución", como las de solución de controversias y otras que por su naturaleza operan después de la resolución del contrato.

\subsection{EXPLICACIÓN DE LA METODOLOGÍA SEGUIDA}

64. A partir de un importante "temor" (1), se trata de plasmar esta regla de acuerdo a una metodología admitida por el Common Law (2), y que la jurisprudencia se ha encargado de confirmar (3).

\section{(1) Motivo del temor}

65. Se tuvo a la vista la enorme dificultad técnica que significa la resolución del contrato en estipulaciones contractuales como las cláusulas compromisorias, penales y demás multas, la lex fori e incluso la acción indemnizatoria. Todas ellas tendrían que desaparecer como consecuencia de la retroactividad ${ }^{44}$.

(2) La decisión admitida por el legislador y su justificación técnica: doctrina de las severable clauses

66. Esto ha llevado a entender las cláusulas como "separables" del resto del contrato. Tal afirmación se ha hecho por la United States District Court for the Southern District of New York, en el caso Filanto S.p.A. v. Chilewich Int'l Corp. ${ }^{45}$, aplicando el art. 81 ap. 1 CISG:

“(...) contracts and the arbitration clauses included therein are considered to be 'severable', a rule that the Sale of Goods Convention adopts with respect to avoidance of contract generally".

\section{(3) Algunas aplicaciones jurisprudenciales}

67. La jurisprudencia ha aplicado la excepción, habilitando una cláusula "en virtud de la cual un vendedor que no procediera a la entrega debía abonar ciertas sumas al comprador" (Corte de Arbitraje Cámara de Comercio Internacional, Laudo N 9978, marzo 1999), y

44 Comentarios del Secretariado CISG, art. 81, ap. 1, No 4.

45 Filanto S.p.A. v. Chilewich Int'l Corp., 789 F. Supp. 1229, 1239 (1992), appeal dismissed 984 F. 2d 58 (2d Cir. 1993). 
otras que obligan a devolver las mercaderías u otros artículos ya entregados en cumplimiento del contrato (Obester Gerichshof, Austria, sent. 29.6.1999).

\section{EVALUACIÓN}

68. Debemos formular nuestros reparos a las soluciones adoptadas por los textos internacionales comentados (3.1), luego de lo cual explicaremos lo que en nuestro concepto debe ser el verdadero alcance que debe brindarse a la retroactividad en la resolución del contrato (3.2).

\subsection{Sobre la REGLA DE LA IRRETROACTIVIDAD}

69. El tratamiento brindado por las legislaciones comunitarias puede explicarse a partir de las excepciones que ellas mismas contemplan, y que a nuestro entender no son plenamente satisfactorias.

1. En efecto, se aprecia una suerte de temor hacia la aplicación de la retroactividad. El legislador comunitario entiende que el rigor de la retroactividad puede generar la inhibición del derecho de reclamar los perjuicios resultantes del incumplimiento contractual. Ante esta dificultad es que procede realizando algunas "concesiones" teóricas, recurriendo a las excepciones.

2 Ese temor es doble, porque duda de calificar a la resolución como un modo de extinción total del contrato, indicando simplemente que se extinguen hacia el futuro "las obligaciones" de los contratantes y ciertas cláusulas referidas.

3. Esa pretendida irretroactividad no queda suficientemente diseñada a partir de las normas en debate. Creemos que se alude a dos ideas más bien distintas:

a) El derecho a la indemnización no compromete en principio lo que se ha ejecutado en el pasado contractual. En ninguna forma la concesión de una indemnización de perjuicios decide la suerte del vínculo contractual ${ }^{46}$.

b) En efecto, la estructura esencial del contrato viene a ser destruida por la resolución; pero se deja a salvo un pequeño sustrato de cláusulas que son de utilidad evidente e indispensable para gobernar de la manera eficiente la ruptura del vínculo contractual.

70. La retroactividad es necesaria para que opere en forma apropiada la transferencia de las cosas en las obligaciones condicionales de efecto resolutorio, así como para que los

46 Para el Derecho argentino: Ovejero, Belarmino R. v. Rattaro, Gustavo F., s / resolución de contrato, Cámara Civil y Comercial de San Martín, 2a Sala, 19.6.2003, BA B2002581, citado en Morello, Augusto, op. cit. (n.15), XVIII, p. 249 , n. 526. 
contratantes puedan recuperar sus respectivas prestaciones y terminar de extinguir su vínculo contractual. Y aquí está su exclusiva utilidad.

\subsection{AlCANCES DE LA RETROACTIVIDAD}

71. Podrá pensarse que se trata de un problema simplemente conceptual, en el entendido que por la resolución se "extingue" el contrato de todos modos, con efecto retroactivo. Pero el problema parece ser algo más que semántico.

Parece ser que el problema aquí consiste precisamente la extensión que se brinda a esa extinción del contrato. Si lo consideramos como nunca existente, ¿no significará tampoco que no podremos hacer aplicación de esas cláusulas?

72. Ante esta dificultad, se parece optar por una solución pacífica: se resuelve el contrato hacia el futuro, restituyéndose lo dado anteriormente, y bajo salvedad de las estipulaciones anteriores. La técnica opera como una transacción teórica, negando el principio de la retroactividad, y aplicándose de manera supuestamente exclusiva a las restituciones, en el hecho significó admitirlo por la puerta trasera.

El problema podría ser solucionable revisando una vez más las excepciones a la retroactividad. Una vez delimitada la dificultad, parece más lógico optar por la incidencia de la resolución solamente en las obligaciones integrantes del contrato, que disponer una suerte de "excepción a la retroactividad" en ellas. Del mismo modo, parece técnicamente forzada una proposición de ultraactividad del contrato resuelto, especialmente para aquellas cláusulas que integran la llamada etapa postcontractual.

73. No podemos dejar de destacar la necesidad de interpretaciones que presten alguna utilidad a las partes, lo cual constituye un imperativo en materia de interpretación contractual (CCch., art. 1562). Pero es un deber superar el superficial análisis que se hace de los efectos de la resolución del contrato, y solo un atento estudio de estas normas permitirá descifrar adecuadamente cuáles son los contornos e identidad de esos efectos.

En el fondo, con esta reconfiguración en la retroactividad, se reproduce el mismo pasaje escrito por Julio Cortázar:

\author{
No estarás para nada, \\ no serás ni recuerdo, \\ $y$ cuando piense en ti \\ pensaré un pensamiento \\ que oscuramente \\ trata de acordarse de ti.
}

("El Futuro"). 


\section{REFERENCIAS BIBLIOGRÁFICAS}

Alessandri R., Arturo, Somarriva U., Manuel y Vodanovic H., Antonio. Tratado de las Obligaciones. Volumen de las Obligaciones en General y su diversas clases -2a Edición- Santiago, Chile: Editorial Jurídica de Chile, 2001, T. I.

De la Compraventa y de la Promesa de Venta -2a Edición- Santiago, Chile: Editorial Jurídica de Chile, 2003, T. II, Vol. 2.

La Nulidad y la Rescisión en el Derecho Civil Chileno -2a Edición- Santiago, Chile: Ediar Editores Ltda., s/f, T. II.

ÁlVArez VigaraY, Rafael. La Resolución de los Contratos Bilaterales por Incumplimiento. Granada, España: Editorial Comares, 1986.

Bonivento FernándeZ, José Alejandro. "Breves apuntaciones al Libro VII -Fuentes de las Obligaciones- del nuevo Código Civil del Perú 1984”. En: VV. AA. El Código Civil Peruano y el sistema jurídico latinoamericano. Ponencias presentadas en el Congreso Internacional celebrado en Lima del 9 a 11 de agosto de 1985 organizado por la Facultad de Derecho y Ciencias Políticas de la Universidad de Lima y la Associazione di Studi Sociali Latinoamericani (ASSLA). Lima, Perú: Cultural Cuzco Editores, 1986, Nº 6, p. 359.

Borda, Guillermo A. Tratado de Derecho Civil: Contratos (Colab. Alejandro Borda). Buenos Aires, Argentina: Editorial LexisNexis Abeledo-Perrot, 2005, T. I.

Catsán Tobeñas, José. Derecho Civil Español, Común y Foral: Derecho de las Obligaciones. La Obligación y el Contrato en General (revisada y puesta al día por Gabriel García Cantero) -16a Edición- Madrid, España: Editorial Reus, 1992, T. III .

Castelblanco Koch, Mauricio Javier. Las Obligaciones Restitutorias del Código Civil y la Inflación. Santiago, Chile: Editorial Jurídica de Chile, 1979.

Clemente Meoro, Mario. La Resolución de los Contratos por Incumplimiento. Estudio comparativo, doctrinal y jurisprudencial del Derecho Inglés y del Derecho Español. Valencia, España: Editorial Tirant lo Blanch, 1992.

Díez-Picaso, Luis, Roca, Encarna y Morales Moreno, Antonio. Los Principios del Derecho Europeo de los Contratos. Madrid, España: Editorial Civitas, 2002.

Ehmann, Horst y SuTSCHet, Holger. La Reforma del BGB. Modernización del Derecho Alemán de Obligaciones (Trad. Claudia López Díaz y Ute Salach de Sánchez). Bogotá, Colombia: Ediciones Universidad Externado de Colombia, 2006.

Espina O., Alberto y Quintana H., Alejandro. Compraventa Internacional de Mercaderías. Análisis de la Convención de las Naciones Unidas. Santiago, Chile: Editorial Jurídica de Chile, 1985.

Garro, Alejandro A. M. (director) y VeYTIA P., Hernany (colab.). Principios UNIDROIT sobre los Contratos Comerciales Internacionales - 2a Edición- Roma, Italia: Universidad Nacional Autónoma de México - Instituto de Investigaciones Jurídicas, UNIDROIT, Centro Mexicano de Derecho Uniforme, 2004.

GatiCa PACHECO, Sergio. Aspectos de la Indemnización de Perjuicios por Incumplimiento del Contrato (Del incumplimiento de las obligaciones contractuales; de los perjuicios y de su liquidación judicial, legal y convencional. De la cláusula penal. Artículos 1556, 1558, 1559 y 1535 a 1544 del Código Civil). Santiago, Chile: Editorial Jurídica de Chile, 1959.

Hedemann, J. W. Derecho de Obligaciones (Trad. Jaime Santos Briz). Madrid, España: Editorial Revista de Derecho Privado, 1958, Vol. III.

JOSSERAND, Louis. Derecho Civil. Teoría General de las Obligaciones (revisado y complementado por André BRUN; traducción Santiago Cunchillos y Manterola). Buenos Aires, Argentina: Ediciones Jurídicas Europa-América, T. II, Vol. 1.

López SANTA MARÍA, Jorge. Obligaciones y Contratos frente a la Inflación. Santiago, Chile: Editorial Jurídica de Chile, 1978. 
MOnTORY BARrigA, Gonzalo. "Las Ficciones Jurídicas", en: Revista de Derecho, № 12, pp. 97-109. Concepción, Chile: Universidad Católica de la Santísima Concepción, Facultad de Derecho, 2004.

Morello, Augusto Mario. Ineficacia y Frustración del Contrato (Colab. Pedro Rafael de la Colina) -2a EdiciónLa Plata, Argentina: Librería Editora Platense y Editorial LexisNexis Abeledo- Perrot, 2006.

PANTAleón, Fernando. "Resolución por Incumplimiento e Indemnización”, en: Anuario de Derecho Civil, T. XLII, fascículo IV, Nº 4. Madrid, España: Ministerio de Justicia y Consejo Superior de Investigaciones Científicas, octubre-diciembre, 1989.

Planiol, Marcel, Ripert, Georges, y Esmein, Paul. Traité Pratique de Droit Civil Français. París, Francia: Librairie Générale de Droit et de Jurisprudente, 1930, T. VI.

Pothier, Robert Joseph. Tratado de las Obligaciones (Trad. M. C. De las Cuevas). São Paulo, Brasil: Editorial Heliasta S. R. L., 1993.

RoCHFELD, Judith. "Inejecución de las Obligaciones" (arts. 1157 a 1160 - 1). En: VV.AA. Del Contrato, de las Obligaciones y de la Prescripción. Anteproyecto de Reforma del Código Civil Francés. Libro III, Títulos III y XX (Trad. Fernando Hinestrosa). Bogotá, Colombia: Universidad Externado de Colombia, 2006.

Vidal Olivares, Álvaro. La Protección del Comprador. Régimen de la Convención de Viena y su contraste con el Código Civil. Valparaíso, Chile: Ediciones Universitarias de Valparaíso, 2006.

Zimmermann, Reinhard. The New German Law of Obligations. Historical and Comparative Perspectives. Oxford, Reino Unido: Oxford Claredon Press, 2005. 